\title{
Antonio Candido na Unicamp
}

\section{Carlos Vogt}

Universidade Estadual de Campinas

\begin{abstract}
A
cho que, de um ponto de vista mais subjetivo, as coisas aconteceram quero dizer, as coisas relacionadas com o tema em questão -, quando eu vim de Sales Oliveira para Ribeirão Preto, depois para São Paulo para fazer o curso de Letras, na antiga Faculdade de Filosofia, Ciências e Letras da USP, à rua Maria Antonia.
\end{abstract}

Foi lá, em 1962, que conheci o professor Antonio Candido, no curso de Teoria Literária e Literatura Comparada que ele oferecia para o primeiro ano dos alunos do curso de Letras. Segui seu aluno, regular, ouvinte, irregular, em toda a graduação e, nos anos 1968 e 1969, fui também seu estudante no programa do curso de pós-graduação em que, além dele, brilhavam os astros e as estrelas de Gilda de Mello e Souza, Paulo Emílio Sales Gomes, Rui Coelho e Oswaldo Elias Xidieh.

Isso tudo acontecendo no cenário político da ditadura militar que recrudescia no país e que, na cena da FFCL, se manifestava na ação violenta da polícia, abrigada pelo Comando de Caça aos Comunistas (CCC) no vizinho Mackenzie, e que resultou na destruição das condições de funcionamento e no consequente fechamento dos prédios, além da morte do estudante secundarista José Carlos Guimarães, do ferimento, também por bala, de estudantes universitários e de uma grande quantidade de feridos entre os participantes do que ficou conhecido como A batalha da Maria Antonia.

Em 1968, o prédio da Maria Antonia, ocupado pelos estudantes, ressoava os acontecimentos internacionais da França e dos Estados Unidos e era palco do movimento das paritárias em que discutíamos a reforma do ensino superior, a 
abolição da cátedra e de outros componentes institucionais e comportamentais da verticalidade que então caracterizava a estrutura e o funcionamento da universidade no Brasil.

Em 1969, já no segundo ano do curso de pós-graduação, fomos para o prédio da Geografia e História, na Cidade Universitária. No primeiro semestre, o professor Candido estava nos EUA, como convidado acadêmico em Yale, se bem me lembro, como já acontecera em parte do ano anterior. Foi assim que tive, neste último caso, a oportunidade de ser aluno do professor Xidieh que, a convite do professor Candido, o substituía, e da professora Gilda de Mello e Souza, substituindo-o, também, em algumas aulas e seminários sobre estética que, em 1969, já ocorriam na Cidade Universitária.

No curso de graduação na USP, havia sido aluno do professor Albert Audubert, na antiga cadeira de francês.

Por várias vezes, o professor Audubert tinha me proposto ir para a França com uma bolsa do governo francês. Devido a compromissos econômicos e financeiros que eu já contraíra, não encontrava, apesar do desejo de aceitar a oferta, meios para sair do país só como bolsista.

Mais ou menos no meio do ano de 1969, depois de um encontro com o professor Audubert, combinei com ele retomarmos o assunto da viagem à França. Em agosto, quando fui visitá-lo em seu apartamento na Alameda Santos, deu-me a notícia de que Universidade Estadual de Campinas - a Unicamp -, criada três anos antes, em 1966, estava desenvolvendo um programa para a implantação, no Instituto de Filosofia e Ciências Humanas (IFCH), de um Departamento de Linguística. Queria indicar o meu nome para integrar um grupo de quatro pessoas que seriam contratadas pela Unicamp e seguiriam para Besançon, com uma bolsa da Fundação de Amparo à Pesquisa do Estado de São Paulo (Fapesp), para fazerem uma licenciatura e um mestrado em linguística.

Convite aceito, fui a Campinas, com uma carta de apresentação do professor Audubert, procurar o professor Fausto Castilho, coordenador e um dos fundadores do IFCH, além de responsável pela criação do programa de linguística na universidade, tendo estado ele próprio em Besançon onde fortaleceu o seu entusiasmo intelectual e acadêmico com as possibilidades epistemológicas da boa convivência da linguística com a lógica e com a matemática. Essa convivência, que certamente ajudou a embasar o apodo de ciência-piloto com que a linguística foi apresentada durante um bom tempo, principalmente na efervescência do estruturalismo europeu nas décadas de 1960 e de 1970, aliada às circunstâncias de ter o professor Castilho convivido com a experiência viva dos estudos que então se produziam na França, tudo isso contribuiu para que o modelo teórico e metodológico a ser implantado na Unicamp buscasse reproduzir, em Campinas, o que vinha acontecendo no cenário internacional no campo da linguística e das ciências humanas, em geral.

Ao conversar com o professor Castilho, informei-lhe também ser aluno do professor Candido, o que o deixou bastante satisfeito, já que, como eu viria a 
saber na sequência de nosso diálogo, era ele um dos responsáveis pela orientação do processo de formação do que viria, mais tarde, a ser chamado "Grupo de Campinas" que, na verdade, se constituiu em duas etapas: na primeira, em 1968, contrataram-se pela Unicamp e seguiram para Besançon, com bolsa da Fapesp, os professores André Villalobos, Angelo Barone, Antonio Augusto Arantes e Luiz Orlandi; na segunda, em 1969, os professores Carlos Franchi, Haquira Osakabe, Rodolfo Ilari e eu próprio.

Os integrantes da primeira turma vinham de áreas diferentes: um da sociologia, outro da matemática, o terceiro da antropologia e o último da filosofia; os da segunda vinham de letras, sendo que Franchi era também formado em Direito.

A ideia de enviar pessoas com origens acadêmicas diversas para o mesmo centro de estudos linguísticos atinha-se ao que foi dito antes a propósito da concepção da linguística como ciência piloto na grande área das Humanas e, mais especificamente, no caso da Unicamp, à própria concepção dos cursos de graduação, que suponham um studium generale, como gostava de dizer o professor Fausto Castilho, um ciclo básico, como ficou tecnicamente chamado, com matérias comuns a todos os cursos oferecidos pelo IFCH.

Quando falei com o professor Candido que tinha estado em Campinas com o professor Fausto Castilho por recomendação do professor Audubert, recebi dele a aprovação imediata e firme, logo concretizada numa carta de referência que passou a ser para mim como que um documento de minha identidade acadêmica, institucional e intelectual que por ele se constituía e se fundava, restando para a frente a responsabilidade de lhe fazer jus e a satisfação de tê-lo obtido para o desafio de poder merecê-lo.

O professor Antonio Candido indicou ou avalizou todos os nomes dos que constituíram o Grupo de Campinas.

No caso da segunda turma, a Fapesp, fundada então havia poucos anos, em 1962, não internalizara ainda de todo, na sua dinâmica de fomento à pesquisa, o apoio sistemático às Humanidades e tampouco tinha no seu escopo de ação financiar programas institucionais como esse da Unicamp para a formação de quadros docentes já contratados pela universidade.

A primeira turma tinha passado; agora, uma segunda leva, repetindo a dose, não seria tão fácil de passar pela aprovação da Fapesp e de seus dirigentes, em especial o seu diretor científico, na época o professor Oscar Sala, do Instituto de Física, da USP.

Aqui, a persistente insistência do professor Fausto Castilho e a tranquila e firme convicção da importância do projeto que tinha o professor Candido, aliada ao profundo respeito de que sempre gozou entre todos com quem convivia na vida institucional, acadêmica e intelectual, levaram a fazer ceder os argumentos de resistência da Fapesp e as bolsas foram aprovadas e concedidas.

Quando voltamos, com os objetivos acadêmicos cumpridos e assumimos as atividades no Departamento de Linguística, logo em 1972, a Unicamp enfrentou sua primeira crise institucional, tendo o professor Zeferino Vaz, seu reitor, sobre- 
vivido a ela e conseguido afastar da universidade vários professores que lhe eram adversos, entre eles o professor Fausto Castilho, que mais tarde seria, na gestão do professor Pinotti, reintegrado à instituição.

Durante todo o processo crítico por que passou a universidade, a referência em que para ela se constituiu o professor Antonio Candido foi fundamental para que as coisas retomassem o seu ritmo de normalidade produtiva, particularmente nas humanidades, bastante envolvidas no desenrolar dos acontecimentos que pautaram a crise.

O fato é que o professor Zeferino Vaz tinha pelo professor Candido um enorme apreço intelectual, pessoal e existencial e já havia feito, desde sua vinda para Campinas, algumas tentativas de sedução institucional para trazê-lo para a Unicamp.

O professor Antonio Candido não vinha, mas se mantinha reciprocamente atencioso para com o professor Zeferino Vaz, para com a Unicamp e, especialmente, para com o projeto do Grupo de Campinas.

Entre 1974 e 1976, os quatro integrantes da segunda turma do "Grupo" fizeram seus doutorados com viagens e estadas em instituições internacionais, sempre com o apoio institucional do professor Zeferino Vaz e o aval acadêmico do professor Antonio Candido.

A Unicamp crescia e já passara por sua primeira crise de adolescência institucional. Saíra-se bem e o que não se resolveu no imediato foi sendo resolvido depois, como a volta do professor Fausto Castilho acima referida.

O número de alunos aumentava com o número de cursos de graduação e de pós-graduação oferecidos e os departamentos discutiam suas necessidades de aumento das cargas horárias para as disciplinas específicas de cada curso de bacharelado e de licenciatura. Aos poucos, a concepção de curso que suponha o conjunto de disciplinas básicas comuns para as grandes áreas acadêmicas ia perdendo força e fortalecendo a tendência para o nascimento de institutos e faculdades do que até então se organizava como departamento.

No estatuto da Unicamp e em seu plano diretor estava prevista a criação de uma Faculdade de Letras, cujo desenho geral era coincidente com o que tradicionalmente caracteriza as instituições da área: vários departamentos, tantos quantos forem as pressões internas e externas para a sua criação e proliferação. Uma estrutura institucional feita, portanto, de justaposição de peças.

Para tentar evitar que o mesmo ocorresse na Unicamp e fugir, assim, do que o seu plano diretor previa e na época ameaçava desencadear, o Departamento de Linguística, do qual me tornei chefe logo em seguida à obtenção do doutorado, em 1974, propôs-se, ainda no IFCH, a começar a oferecer cursos de bacharelado e de licenciatura em Letras (língua portuguesa e literaturas brasileira e portuguesa).

Para isso era preciso, além do que o Departamento de Linguística já oferecia, oferecer latim e as literaturas da grade curricular. O professor de latim foi contratado e deu-se início, com o apoio e a orientação do professor Candido, ao proces- 
so de contratação dos professores que viriam atender a necessidades relativas às aulas de literatura brasileira e literatura portuguesa, constituindo-se, assim, um grupo que marcou época na história da Unicamp e que seria o núcleo inicial do futuro Departamento de Teoria Literária.

Faziam parte do grupo, mesmo que vindos em momentos, às vezes, diferentes, os professores Adélia Bezerra de Meneses, Antonio Arnoni Prado, Berta Waldman, Edda Arzua Ferreira, Jesus Durigan, João Luiz Lafetá, José Miguel Wisnik, Maria Lucia Dal Farra, Marisa Lajolo, Modesto Carone, Roberto Schwarz, Suzi Frankl Sperber, Vera Chalmers e Yara Frateschi Vieira.

O Departamento de Linguística havia recebido, algum tempo antes, também vários professores do programa de pós-graduação do Museu Nacional, entre eles, Aryon Rodrigues, Brian Head e Antonio Carlos Quícoli, já contando em seu quadro com os professores Ataliba Castilho, que viera de Marília e Marcelo Dascal, voltando de Israel.

Não faltava, pois, densidade crítica ao departamento, onde, ao contrário, sobravam competências para as quais era preciso e desejável desenhar um novo espaço institucional que pudesse abrigá-las mais adequadamente e onde pudessem exercer suas atividades intelectuais e acadêmicas com mais proveito para os objetivos de ensino e pesquisa da universidade.

Conversávamos muito com o professor Zeferino Vaz a respeito da conveniência da criação da unidade de Letras, tal como prevista no plano diretor e da oportunidade de se criar na Unicamp algo novo, a partir do que já se desenvolvia no Departamento de Linguística que, agora, agregava também o grupo de teoria literária, oferecendo, além do bacharelado em linguística, a licenciatura em Letras - português, língua e literatura.

O professor Zeferino Vaz mostrava-se sensível aos argumentos que lhe eram apresentados e penso que aquele que de fato o convenceu, e mesmo persuadiu, foi o da possibilidade de termos o professor Antonio Candido como coordenador dos trabalhos para a criação e implantação da nova unidade, concebida fora do modelo tradicional e sobre a experiência que então se desenvolvia no próprio Departamento de Linguística, cujas feições institucionais e acadêmicas já se modificavam pela presença do grupo de teoria literária.

Pude, nessa ocasião, dizer ao professor Zeferino Vaz que estávamos diante da oportunidade única de trazer o professor Candido para dirigir o novo instituto, desde que este evitasse a tradicional segmentação das faculdades de Letras e refletisse as experiências que já se realizavam na Unicamp, tanto do ponto de vista das práticas de ensino, que associavam linguística e literatura, como do ponto de vista teórico, que fundamentava as referidas práticas dando-lhes organicidade estrutural e funcional.

Para ganharmos tempo institucional, e como estratégia para alongar o prazo de aplicação do estatuto da universidade que previa a criação do Instituto de Letras, foi acordado com o professor Zeferino Vaz que fosse nomeado coordenador desse instituto o professor Manoel Tosta Berlinck, então diretor do Instituto de 
Filosofia e Ciências Humanas, ao qual pertencia o Departamento de Linguística, do qual eu era chefe, tendo sido nomeado também coordenador associado do referido Instituto de Letras.

Em outubro de 1975, encaminhávamos ao professor Zeferino Vaz um anteprojeto para a implantação do Instituto de Letras que, além dos cursos de graduação e pós-graduação já oferecidos pelo Departamento de Linguística, ainda no IFCH, propunha a criação de uma graduação, licenciatura em português e literatura de língua portuguesa, e de uma pós-graduação em teoria literária, com ligações em áreas conexas da linguística e das ciências humanas.

O cronograma apresentado nesse anteprojeto, cuja elaboração se deveu ao grupo de teoria literária, sob a orientação do professor Antonio Candido, era o seguinte:

a) Agosto de 1976 - Abertura de inscrição e seleção para o curso de pósgraduação (mestrado em Letras - área de concentração em teoria literária), com número de vagas a ser oportunamente fixado.

b) Março de 1977 - Início do curso de pós-graduação.

c) Novembro de 1976 - Fim do currículo provisório para a adaptação dos bacharéis em linguística à licenciatura em português.

d) Março de 1977 - Início do currículo definitivo para licenciatura em português e literatura em língua portuguesa, oferecido com opção para alunos do IFCH (curso básico), e ainda sem realização de vestibulares.

e) Janeiro de 1978 - Primeiro vestibular para o Instituto de Letras, com número de vagas a ser oportunamente fixado.

Caminhava-se, desse modo, para a formalização do Instituto de Letras sob uma nova configuração acadêmica que, então, já superava a possibilidade de se ver na Unicamp a adoção do modelo tradicional das faculdades de Letras que todos queríamos evitar.

O fato decisivo para essa mudança de rota deu-se com a aceitação, pelo professor Candido, do convite que mais uma vez lhe fazia o professor Zeferino Vaz para dirigir a nova unidade de ensino e pesquisa da Unicamp.

Tive a honra, a distinção e, sobretudo, o prazer e a alegria de ter recebido do professor Zeferino Vaz a tarefa de tentar convencer o professor Candido a aceitar o convite, o desafio e a aventura acadêmica da criação e implantação não apenas de uma nova unidade na Unicamp, mas de uma totalmente nova concepção da unidade que se iria implantar.

Num fim de tarde, já anoitecendo, fui, como havia combinado com ele, à casa do professor Candido, à rua Bryaxis, antiga rua Alice, no Itaim Bibi, para voltarmos, na conversa, ao assunto unicampense.

Ali, na sala de estar, contígua à sala de jantar, onde a mesa, também de trabalho, emoldurada pelas estantes que traziam parte da biblioteca de dona Gilda e do professor Candido, onde estivera várias outras vezes para os encontros amigos 
e de orientação, enfatizei, na conversa, o argumento de que a única possibilidade de alteração do modelo de Letras a ser implantado em Campinas era a de que o professor Candido aceitasse dirigir o novo projeto e coordenasse a equipe a que seria dado concebê-lo e desenhá-lo para substituir o que estava previsto no estatuto da universidade.

Não era só um argumento; era também um fato, pois o reitor da Unicamp dizia, com convicção e firmeza, que a condição para aceitar e encaminhar a mudança era ter o professor Candido a conduzi-la. Do contrário, dizia ele, nada feito!

Com o seu jeito cortez, afável, bem-humorado, seguro na dúvida e na certeza, o professor Antonio Candido, chamando-me Carlinhos, como sempre fez, no carinho protetor e habitual do tratamento com os seus alunos, estudantes e amigos, disse-me, então, que aceitava. E a conversa seguiu, já ali mesmo, antecipando, no que ele dizia, as linhas mestras que dariam sustentação ao que depois viria ser, logo no futuro imediato, o Instituto de Estudos da Linguagem (IEL), com uma proposta que consolidava a que estava contida no anteprojeto do Instituto de Letras, acima mencionado, avançando-a no sentido de uma superação, e da realização de uma grande novidade acadêmica no cenário institucional da educação superior no estado de São Paulo e no país.

No dia 30 de novembro de 1976, o professor Wilson Cano, que sucedera o professor Manoel Berlinck na direção do IFCH, e eu próprio, na qualidade de chefe do Departamento de Linguística, enviávamos ao professor Zeferino Vaz o projeto de constituição do Instituto de Estudos da Linguagem, elaborado sob a coordenação do professor Antonio Candido de Mello e Souza que, como consta do ofício de encaminhamento, deveria, pelos entendimentos mantidos com o reitor Zeferino Vaz, assumir a futura direção desse instituto.

O ofício do professor Candido, também datado de 30 de novembro de 1976, dirigido ao professor Zeferino Vaz, trazia:

Magnífico Reitor:

Tenho a honra de passar às suas mãos a proposta de um Instituto de Estudos da Linguagem, nome que nos pareceu mais adequado a uma concepção renovadora que o de Instituto de Letras, anteriormente previsto, por motivos que Vossa Magnificência verá expostos no documento anexo.

Este provém das atividades da comissão eleita pelos docentes de Lingüística e de Teoria Literária a fim de elaborá-lo. Como convidado por Vossa Magnificência para coordenar oportunamente a implantação do novo Instituto, atendi ao chamado dos colegas para presidir os trabalhos e, a partir da primeira quinzena de outubro, tivemos reuniões semanais, de que resultaram alguns documentos e notas preparatórias, bem como extensa troca de idéias. A seguir, o texto foi apresentado, para apreciação e comentário, a uma assembléia de docentes daquelas disciplinas, que o discutiram amplamente e propuseram modificações. A redação final encaminhada agora à alta consideração de Vossa Magnificência e dos órgãos competentes, representa, assim, o resultado de um processo que lhe assegurou elevado teor consensual.

Neste ensejo, apraz-me ressaltar a dedicação dos membros da comissão, a cuja lucidez e espírito universitário se deve o presente documento, e que são os seguintes colegas: Aryon Dall'Igna 
Rodrigues, Ataliba Teixeira de Castilho, Carlos Alberto Vogt, Haquira Osakabe, Maria Lúcia Dal Farra, Vera Maria Chalmers, Yara Frateschi Vieira.

Queira Vossa Magnificência aceitar a expressão dos meus sentimentos de perfeita estima e real consideração.

a) Antonio Candido de Mello e Souza

\section{O documento, definindo o IEL, dizia, curta e objetivamente:}

Unidade de ensino e pesquisa, nos níveis de graduação e pós-graduação, destinada a formar docentes e pesquisadores no domínio dos estudos sobre a linguagem humana em suas diversas manifestações.

\section{No capítulo da justificativa, o documento anotava:}

A proposta de criação, na Unicamp, de um Instituto de Estudos da Linguagem tem como objetivo fundamental: assegurar as condições para o desenvolvimento da pesquisa e do ensino, nas áreas do conhecimento que tenham por denominador comum o fenômeno da linguagem humana nos múltiplos aspectos da sua natureza complexa (físicos, biológicos, psíquicos, sociais, estéticos) e nos usos culturais que dela fazem as diversas comunidades.

$\mathrm{Na}$ base desta concepção, está o intuito de propor um modelo diferente do que foi elaborado no Brasil no começo do decênio de 1930 e vem sendo aplicado, desde então, com variantes maiores ou menores. Tal modelo, de cunho enciclopédico, previa unidades demasiado abrangentes, que compreendiam a criação simultânea, em pé de igualdade teórica, de um grande número de cursos de línguas e literaturas, sem definir uma base comum que regesse o seu entrosamento e desenvolvimento. Embora se justifique à luz do momento histórico e tenha prestado serviços relevantes, tal modelo foi superado, como era natural, por concepções novas, devidas sobretudo ao progresso de duas disciplinas gerais, a Lingüística e a Teoria Literária. São elas que propomos para núcleo de um novo Instituto, cuja estrutura deve ser concebida como entrosamento orgânico de atividades, não como justaposição mecânica.

A Lingüística se distinguiu nos últimos decênios pelo esforço de constituir um objeto próprio para a prática científica, elaborando métodos adequados para descrever as línguas naturais. Os resultados obtidos permitiram, mais recentemente, utilizar formalismos lógico-matemáticos e métodos hipotético-dedutivos, que aliam o rigor na verificação dos conceitos e noções a um acentuado poder heurístico. Por outro lado, alguns ramos da lingüística (por exemplo: a psicolingüística e a sociolingüística) se beneficiaram das perspectivas e técnicas de outras disciplinas no levantamento e na análise de dados da atividade verbal. Assim, a elaboração da teoria e das técnicas da lingüística tem tido consequêencias importantes para o ensino das línguas e a renovação dos seus métodos, assim como para o estudo do texto literário, fornecendo novos procedimentos de análise e pontos de abordagem, de maneira a constituir um conjunto de informações indispensáveis a qualquer bacharel em estudos literários e lingüísticos.

A Teoria Literária, sob o impacto desta e outras influências, procurou ultimamente dar um cunho científico às especulações sobre o objeto literário, salientando a descrição baseada em critérios objetivos, não valorativos. Com isso, foi possível corrigirem grande parte do que havia de excessivo (não de justificável) em certos exclusivismos teóricos tradicionais, que dilaceravam o estudo da literatura reduzindo-o: (a) a operações de pura erudição filológica e histórica, com pouca capacidade de integrar os resultados da pesquisa, a não ser em esquemas estreitamente deterministas; (b) a dissolver a sua especificidade, devido à hipertrofia do interesse pelo estudo dos fatores externos; (c) a praticar a avaliação pura e simples, com base no critério incontrolável do gosto e da intuição. No entanto, embora seja indispensável incorporar e fecundar a mencionada busca de 
critérios objetivos, convém salientar que estes devem contribuir para aumentar a pertinência do trabalho crítico, mas não para suprimir as suas características próprias. O suporte indispensável à renovação dos estudos literários deve ser uma Teoria Literária capaz de utilizar os procedimentos modernos de delimitação de unidades e definição de seu relacionamento no interior do texto, estimulando ao mesmo tempo a avaliação estética e o senso do seu correlacionamento com os domínios cobertos pelas ciências humanas.

Isso posto, é preciso ressaltar que tanto a Lingüística quanto a Teoria Literária tem por denominador comum a linguagem, ponto de partida do conhecimento propriamente humano, condição do desenvolvimento cultural. Tomada como terreno básico, a linguagem permite a troca de experiências, a fecundação recíproca e a definição de tarefas comuns sem prejuízo das tarefas específicas de cada uma delas. Um Instituto universitário, voltado ao estudo da linguagem humana compreendida em toda a sua plenitude, se caracterizará, pois, pela unidade fundamental do seu objeto, assim como pelos contatos que, a partir do mesmo, se estabelecerão com os demais setores universitários. É importante ressaltar o que há de comum e o que há de diferente, inclusive porque assim será possível focalizar com maior eficiência o problema da formação do especialista em língua e do especialista em literatura, evitando a posição tradicional, em grande parte utópica, do especialista em ambas.

A partir deste núcleo o Instituto poderá aumentar, fundar outros Departamentos, abranger campos cada vez mais numerosos de estudos lingüísticos e literários. Mas isso virá como resultado de um crescimento orgânico, à medida que aparecerem necessidades reais e possibilidades seguras.

Como conseqüência desse espírito, o IEL dará destaque às atividades de pesquisa e à formação de quadros qualificados, privilegiando a pós-graduação. Os modelos tradicionais atacavam ao mesmo tempo, virtualmente, todos os campos de estudo em todos os níveis. Mas uma Universidade jovem deve optar, escolher com firmeza os seus pontos de concentração, visando à excelência. Ora, não é possível alcançar desde logo a excelência em muitos setores e muitos níveis, além disso, os recursos necessários para dar corpo à fórmula proposta aqui são menores do que os exigidos pelo modelo tradicional e sua tendência ao gigantismo.

Resumindo, preconizamos o modelo acima, exposto em suas grandes linhas, por três razões principais:

1. porque permite definir uma filosofia moderna de ensino e pesquisa da língua e da literatura;

2. porque permite concentrar os esforços em setores básicos, de que dependem os demais e, sendo limitados inicialmente, facilitam a busca da excelência;

3. porque a sua implantação é menos onerosa em recursos humanos e materiais que a dos modelos tradicionais.

O parecer do professor Sérgio Porto, à época Coordenador Geral dos Institutos, foi curto e incisivo: "Sou completamente favorável e apoio integralmente o pedido."

Em dezembro de 1976, criava-se o Instituto de Estudos da Linguagem na Unicamp, comportando o Departamento de Linguística, o Departamento de Teoria Literária e o Centro de Linguística Aplicada, que já existia junto ao Departamento de Linguística. Nos anos subsequentes, o Centro deu origem ao Departamento de Linguística Aplicada, no IEL e um novo projeto deu origem ao Centro de Ensino de Línguas (CEL), diretamente ligado à reitoria da Unicamp.

O professor Candido foi designado o primeiro diretor do IEL, tendo como seu associado o professor Carlos Franchi, que o sucedeu, quando o professor Zeferino Vaz, depois de 12 anos na condução da universidade, deixou a reitoria e foi substituído pelo professor Plínio Alves de Moraes. 
O compromisso do professor Candido com o professor Zeferino estava cumprido: o novo Instituto de Estudos da Linguagem estava fundado e implantado. Ficávamos nós com o compromisso de dar seguimento acadêmico e institucional ao que o professor Candido havia criado. Ficávamos também com saudades bem fundadas de sua sábia e generosa presença no cotidiano da juventude do IEL, que cresceu, amadureceu, vingou, guardando o desafio constante de fazer jus à inventividade intelectual, acadêmica e institucional da origem de sua criação. 